\title{
Travel-associated neurological disease terminated in a postmortem diagnosed atypical HSV-1 encephalitis after high-dose steroid therapy - a case report
}

Andreas Osterman ${ }^{1,2^{*+}}$ D , Viktoria C. Ruf ${ }^{3+}$, Cristina Domingo ${ }^{4}$, Andreas Nitsche ${ }^{4}$, Peter Eichhorn ${ }^{5}$, Hanna Zimmermann ${ }^{6}$, Klaus Seelos ${ }^{6}$, Sabine Zange ${ }^{7}$, Konstantinos Dimitriadis $^{8}$, Hans-Walter Pfister ${ }^{8}$, Thorsten Thye ${ }^{9}$, Armin Giese ${ }^{3}$, Dennis Tappe ${ }^{9}$ and Stephan Böhm ${ }^{1,2}$

\begin{abstract}
Background: Human encephalitis can originate from a variety of different aetiologies, of which infection is the most common one. The diagnostic work-up is specifically challenging in patients with travel history since a broader spectrum of unfamiliar additional infectious agents, e. g. tropical disease pathogens, needs to be considered. Here we present a case of encephalitis of unclear aetiology in a female traveller returning from Africa, who in addition developed an atypical herpes simplex virus (HSV) encephalitis in close temporal relation with high-dose steroid treatment.

Case presentation: A previously healthy 48-year-old female presented with confusion syndrome and impaired vigilance which had developed during a six-day trip to The Gambia. The condition rapidly worsened to a comatose state. Extensive search for infectious agents including a variety of tropical disease pathogens was unsuccessful. As encephalitic signs persisted despite of calculated antimicrobial and antiviral therapy, high-dose corticosteroids were applied intravenously based on the working diagnosis of an autoimmune encephalitis. The treatment did, however, not improve the patient's condition. Four days later, bihemispheric signal amplification in the insular and frontobasal cortex was observed on magnetic resonance imaging (MRI). The intracranial pressure rapidly increased and could not be controlled by conservative treatment. The patient died due to tonsillar herniation 21 days after onset of symptoms. Histological examination of postmortem brain tissue demonstrated a generalized lymphocytic meningoencephalitis. Immunohistochemical reactions against HSV-1/2 indicated an atypical manifestation of herpesviral encephalitis in brain tissue. Moreover, HSV-1 DNA was detected by a next-generation sequencing (NGS) metagenomics approach. Retrospective analysis of cerebrospinal fluid (CSF) and serum samples revealed HSV-1 DNA only in specimens one day ante mortem.

(Continued on next page)
\end{abstract}

\footnotetext{
* Correspondence: osterman@mvp.uni-muenchen.de

${ }^{\dagger}$ Andreas Osterman and Viktoria C. Ruf contributed equally to this work.

${ }^{1}$ Max von Pettenkofer Institute, Virology, Faculty of Medicine, LMU Munich,

Pettenkoferstraße 9a, D-80336 Munich, Germany

${ }^{2}$ German Center for Infection Research (DZIF), partner site Munich,

Pettenkoferstraße 9a, D-80336 Munich, Germany

Full list of author information is available at the end of the article
}

(c) The Author(s). 2020 Open Access This article is distributed under the terms of the Creative Commons Attribution 4.0 International License (http://creativecommons.org/licenses/by/4.0/), which permits unrestricted use, distribution, and reproduction in any medium, provided you give appropriate credit to the original author(s) and the source, provide a link to the Creative Commons license, and indicate if changes were made. The Creative Commons Public Domain Dedication waiver (http://creativecommons.org/publicdomain/zero/1.0/) applies to the data made available in this article, unless otherwise stated. 
(Continued from previous page)

Conclusions: This case shows that standard high-dose steroid therapy can contribute to or possibly even trigger fulminant cerebral HSV reactivation in a critically ill patient. Thus, even if extensive laboratory diagnostics including wide-ranging search for infectious pathogens has been performed before and remained without results, continuous re-evaluation of potential differential diagnoses especially regarding opportunistic infections or reactivation of latent infections is of utmost importance, particularly if new symptoms occur.

Keywords: Herpes simplex virus, Next generation sequencing, Encephalitis, Steroid, The Gambia, Travel associated, Yellow fever vaccine associated neurological disease

\section{Background}

Clarification of the aetiology in a timely manner is crucial regarding therapy and outcome of patients presenting with symptoms of encephalitis [1], but also in terms of hygiene measures, post exposure prophylaxis of contact persons, as well as epidemiological (outbreak) control measures. The most common causes of encephalitis are infections, in which viral infections, especially herpes simplex virus type 1 (HSV1 ), account for the majority of cases [2]. However, depending on the geographical region, a different spectrum of pathogens needs to be considered. The standard diagnostic procedures for patients with encephalitis include magnetic resonance imaging (MRI) or computed tomography (CT), analysis of CSF samples as well as electroencephalography (EEG). Moreover, brain biopsy may be sought to confirm an inflammatory process. NGS (next-generation sequencing) techniques are increasingly applied in diagnostics, particularly in complex and unclear cases to identify potential pathogens through metagenomic analyses. These metagenomic analyses detect any fragment of nucleic acid present in a specimen. Bioinformatic downstream analyses can then align these fragments into larger genomes and differentiate them according to human, bacterial or viral origin, for example. Apart from infections, autoantibodies in the context of autoimmune diseases or paraneoplastic syndromes have been increasingly recognized to be associated with encephalitis and have to be included into the differential diagnoses [3]. However, differentiation between infectious and autoimmune encephalitis can be challenging as there may be substantial overlap in their clinical presentation [4]. Here, we report the case of a female traveller with encephalitis of unknown aetiology after a trip to Africa who developed atypical HSV-1 encephalitis in close temporal relation with high-dose steroid therapy.

\section{Case presentation}

A 48-year-old Caucasian previously healthy female without a history of recreational drug use developed confusion syndrome and haemorrhagic cystitis during a travel to The Gambia (Fig. 1). There she presented to a local hospital, where trichomoniasis was diagnosed and treated with antiparasitic chemotherapy. She decided to interrupt the trip and returned to Munich, Germany after only 6 days of travel (corresponds to "day one after onset of symptoms" (DOS 1)). Upon return, the patient was directly referred to a community hospital with dizziness, blurred vision, confusion syndrome, and upper arm pain. In the emergency department, she acutely developed a delirious state with fluctuating vigilance and had to be intubated. Laboratory testing revealed hyponatremia which was carefully corrected. While IL6 was already slightly elevated $(17.7 \mathrm{pg} / \mu \mathrm{l}[<5.9 \mathrm{pg} / \mathrm{ml}])$, CRP $(0.5 \mathrm{mg} / \mathrm{dl}[<0.5 \mathrm{mg} / \mathrm{dl}])$ and body temperature were normal, no rash or neck stiffness were observed (Fig. 2). Based on CSF pleocytosis (CSF cell count 33 cells/ $\mu \mathrm{l}[<5$ cells/ $\mu \mathrm{l}]$, CSF protein $30 \mathrm{mg} / \mathrm{dl}$ [15-45 mg/dl], CSF lactate $2.47 \mathrm{mmol} / \mathrm{l}$ [1.1-2.4 mmol/l], CSF glucose $78 \mathrm{mg} / \mathrm{dl}$ [50-90 mg/dl], intact blood-CSF barrier), empiric antibiotic and antiviral treatment with ampicillin $(12 \mathrm{~g} / \mathrm{d}$ i.v. for 11 days), ceftriaxone ( $4 \mathrm{~g} / \mathrm{d}$ i.v. for 16 days) and acyclovir (750 mg i.v. tid for 3 days) was started immediately upon admission to the emergency room, however, as HSV-PCR was negative and imaging of the head and brain (CT and MRI including angiography) was unsuspicious, acyclovir treatment was ceased after 3 days. Comprehensive microbiological testing for numerous infectious pathogens including tropical and sexually transmissible pathogens, as well as search for autoantibodies were unsuccessful (see Table 1). The results of testing for yellow fever virus were compatible with a previous vaccination which had been administered 10 days before the travel to Africa. The EEG showed patterns of severe diffuse encephalopathy. Since pulmonary gas exchange and protective reflexes were adequate, the patient could be extubated and was respiratory and hemodynamically stable, though still unresponsive and alternating agitated or somnolent. Ten days after the onset of symptoms, the patient was transferred to a university hospital, where microbiological and laboratory testing were intensified. As the aetiology of the encephalitic syndrome was still unclear, steroid pulse therapy was initiated under the rationale of suspected limbic encephalitis 12 days after 


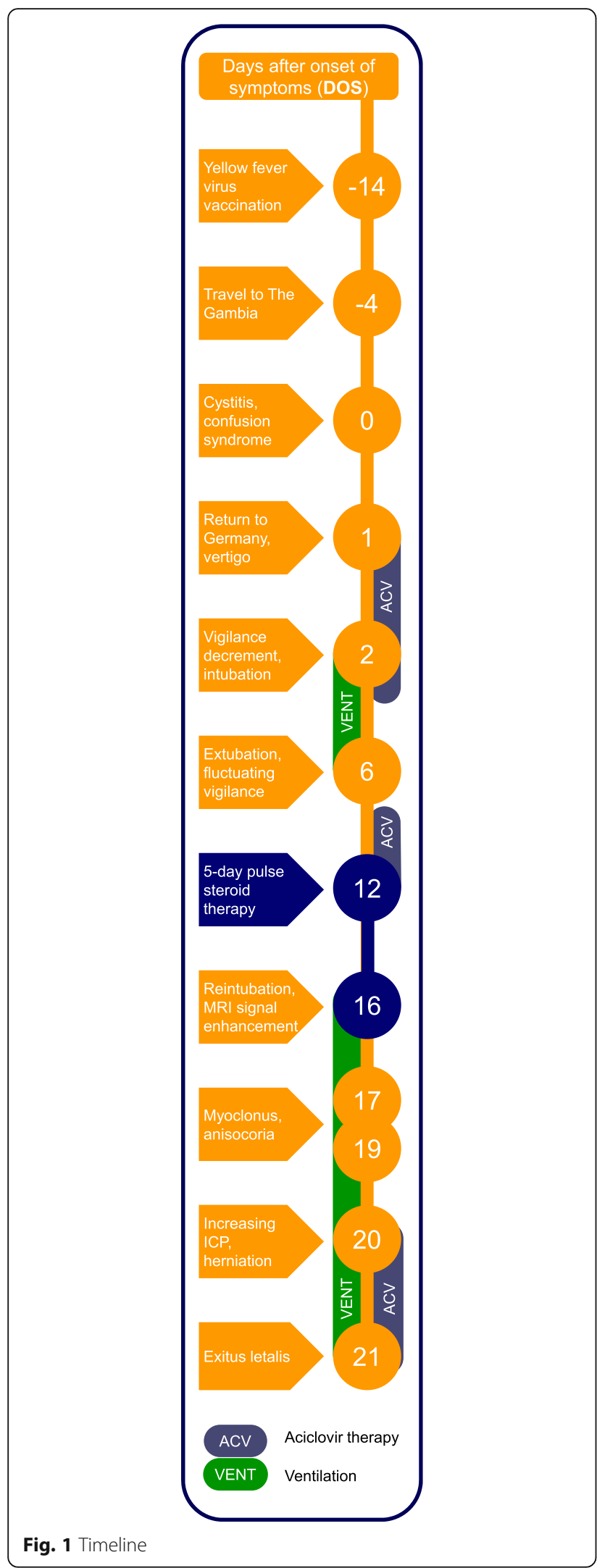

symptom onset and continued for 5 days, but no clinical improvement could be achieved. However, as on MRI new bihemispheric insular and frontobasal signal enhancement appeared (Fig. 3) and since in parallel inflammatory markers started increasing, empiric antibiotic therapy was again applied (meropenem $2 \mathrm{~g}$ i.v. tid from DOS 16 on, vancomycin i.v. [trough level $10-15 \mu \mathrm{g} / \mathrm{dl}$ ] from DOS 18 on). Since the state of vigilance was still unchanged and protective reflexes were absent, the patient was re-intubated. Moreover, facial myoclonus emerged, which was treated with levetiracetam and phenytoin. As the anticonvulsive therapy was insufficient to control the myoclonus, therapeutic sedation was initiated, under which no spikes were detectable any more on EEG. Two days later, anisocoria $(r>l)$ was noticed and conservative treatment of the underlying increased intracranial pressure (ICP) was started with osmotherapeutics, deep anaesthesia (including barbiturate), and hyperventilation. Neurosurgical therapy options were discussed, however, not feasible because of progressive and generalized oedematous brain swelling with transtentorial and foraminal herniation. The patient showed fixed dilated pupils and died 1 day later, 21 days after first symptom onset. As the cause of the disease was completely unclear, autoptic examination was sought which could help to explain at least the final course of the disease. Below, the most important results of the diagnostic investigations are presented and discussed in detail.

\section{Diagnostic focus and assessment Pathogen diagnostics}

During the course of the disease, numerous laboratory examinations were performed in an attempt to identify infectious pathogens potentially responsible for the patient's encephalitis (see Table 1). For this reason, blood, CSF, urine, stool, and respiratory samples were also repeatedly applied to microbiological cultures which did not detect any relevant pathogens. For differential diagnosis, methods were selected according to different criteria: (I) The most common pathogens were analysed by multiplex PCR from CSF (cytomegalovirus (CMV), enterovirus, herpes simplex virus-1/2 (HSV-1/2), human herpes virus 6 (HHV6), human parechovirus, varicella zoster virus (VZV), Escherichia coli K1, Haemophilus influenzae, Listeria monocytogenes, Neisseria meningitidis, Streptococcus agalactiae, Streptococcus pneumoniae, Cryptococcus neoformans/gattii). (II) A group of pathogens was investigated because of the travel history (chikungunya virus, dengue virus, Mycobacterium tuberculosis, Plasmodium sp., rabies virus, Rift Valley virus, sandfly fever virus, Trypanosoma sp., West Nile virus, yellow fever virus, Zika virus) or (III) because of a potential risk profile that could not be specifically asked 


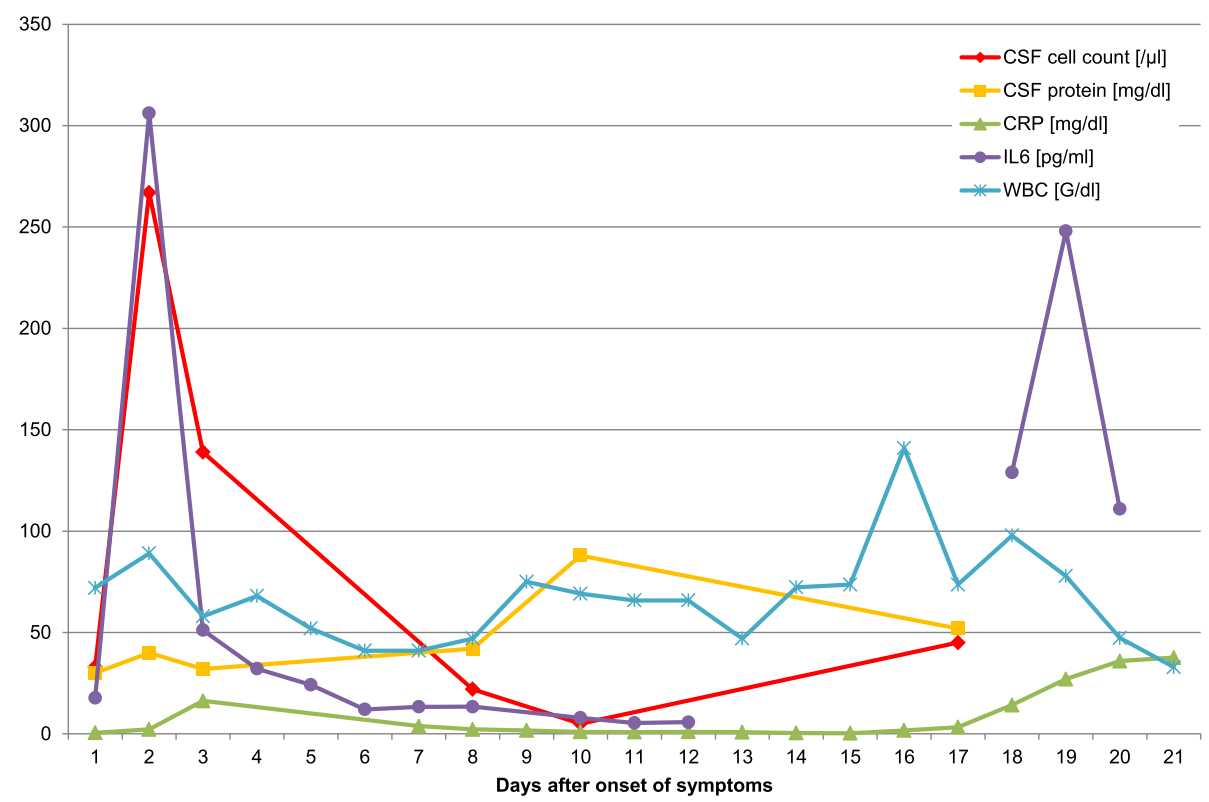

Fig. 2 Laboratory results. Chronological visualization of relevant values from cerebrospinal fluid (cell count $[<5$ cells/ $/$ l] and protein concentration [15-45 mg/dl]), serum (C-reactive protein (CRP) [<0.5 mg/dl] and interleukin 6 (IL6) $[<5.9 \mathrm{pg} / \mathrm{ml}]$ ) and white blood cell (WBC) count [40-104 G/dl]

(HIV, hepatitis viruses, Treponema pallidum). (IV) Moreover, (zoonotic) pathogens which may have been acquired before the journey (Borna disease virus 1 (BoDV-1), Borrelia burgdorferi, Japanese encephalitis virus, Leptospira sp., tick-borne encephalitis virus) or (V) which are rare or very rare pathogens of encephalitis (Ebstein Barr virus, lymphocytic choriomeningitis virus, measels virus, rubella virus) were examined.

\section{Yellow fever vaccine-associated neurological disease (YEL-} AND) and autoimmune encephalitis

Since the patient had received yellow fever vaccination in preparation for her travel, the presence of a yellow fever vaccine associated neurotropic syndrome was considered. Anti-yellow fever antibodies in the patient's serum were within the range of a normal postvaccination immune response and were not detected in the cerebrospinal fluid. No yellow fever vaccine virus RNA could be amplified from any sample (brain biopsies, cerebrospinal fluid, serum, urine). Therefore, YELAND could not be confirmed.

The investigation of a broad spectrum of neuronal autoantibodies (against AMPAR1/2, amphiphysin, aquaporin 4, Ca-channel, CASPR2, CV2 (CRMP5), GABARB1/2, GAD, Hu, LGI-1, Ma1/2, NMDAR, Purkinje cells, Ri, Yo) remained without pathological findings and thus, no evidence for an autoimmune-mediated encephalitis existed.

\section{Autopsy}

On autopsy, neuropathological examination of the brain demonstrated macroscopically oedematous swelling and signs of increased intracranial pressure with sulcal effacement, uncus herniation, and discretely prominent cerebellar tonsils (Fig. 4a). Temporally accentuated haemorrhagic necrosis, which is typically observed in classical cases of herpesviral encephalitis, were not seen (Fig. 4b). Histological examination revealed lymphocytic meningoencephalitis with plenty of perivascular and intraparenchymal T-lymphocytes (Fig. 4c and d). The diagnosis of herpesviral encephalitis was made based on the immunohistochemical detection of numerous infected neurons that stained positive for HSV-1 (Fig. 4e).

\section{NGS analysis}

NGS analysis was performed with DNA and RNA isolated from native autopsy tissue of the frontal lobe and cerebellum together with preserved serum from DOS 21 . The number of reads that could be assigned to viral specimens was highest in material from the frontal lobe (Table 2). The majority of those reads belonged to the human alpha-herpesvirus type 1 (HSV-1) (Fig. 5).

After HSV DNA and antigen were detected in autopsy specimens of the brain by NGS analysis and immunohistochemical detection, respectively, retrospective conventional single PCR analyses from archived CSF, serum and tissue were performed to confirm these results (see below and Table 3).

\section{Discussion and conclusions}

Patients with encephalitis need to be diagnosed and appropriately treated in a timely manner. Viral infections account for the majority of cases (42\%) followed by 
Table 1 Infectious disease work-up

\begin{tabular}{|c|c|c|c|}
\hline Pathogen & DOS & Method & Specimen \\
\hline Borna disease virus-1 & 21 & PCR & CSF \\
\hline Borrelia burgdorferi & 10 & $\lg , \mathrm{Al}$ & CSF, S \\
\hline Chikungunya virus & 10 & $\lg$ & $\mathrm{s}$ \\
\hline Cryptococcus neoformans/gatti & 10 & PCR & CSF \\
\hline Cytomegalovirus & 2,10 & $P C R, \lg , \mathrm{Al}$ & CSF, S \\
\hline Dengue virus & 10,11 & $\lg$ & S \\
\hline Ebstein Barr virus & 10 & $P C R, \lg , \mathrm{Al}$ & CSF, S \\
\hline Enterovirus & 10 & PCR & CSF \\
\hline Escherichia coli K1 & 10 & PCR & CSF \\
\hline Flaviviruses & 21 & PCR & CSF \\
\hline Haemophilus influenzae & 10 & PCR & CSF \\
\hline Hepatitis A virus & 10 & $\lg$ & $\mathrm{s}$ \\
\hline Hepatitis B virus & 10 & $\lg , \mathrm{Ag}$ & $\mathrm{s}$ \\
\hline Hepatitis C virus & 10 & $\lg$ & $\mathrm{s}$ \\
\hline Herpes simplex virus $1 / 2$ & 2,10 & $P C R, \lg , A l$ & CSF, S \\
\hline Human herpes virus 6 & 10 & $P C R$ & $S$ \\
\hline Human immunodeficiency virus & 10 & $\lg , \mathrm{Ag}$ & S \\
\hline Japanese encephalitis virus & 11 & $\lg$ & $\mathrm{S}$ \\
\hline Leptospira sp. & 10 & $\lg$ & S \\
\hline Listeria monocytogenes & 10 & $\mathrm{PCR}$ & CSF \\
\hline $\begin{array}{l}\text { Lymphocytic choriomeningitis } \\
\text { virus }\end{array}$ & 10 & $\lg$ & CSF, S \\
\hline Measels virus & 10 & $\mathrm{Al}$ & CSF, S \\
\hline Mycobacterium tuberculosis & 17 & QFT & B \\
\hline Neisseria meningitidis & 10 & PCR & CSF \\
\hline Parechovirus & 10 & PCR & CSF \\
\hline Plasmodium sp. & 19 & $R T, M$ & $\mathrm{~s}$ \\
\hline Rabies virus & 10 & PCR & CSF \\
\hline Rift Valley virus & 11 & $P C R, \lg$ & $\mathrm{s}$ \\
\hline Rubella virus & 10 & $\mathrm{Al}$ & CSF, S \\
\hline Sandfly fever virus & 10 & $\lg$ & $S$ \\
\hline Streptococcus agalactiae & 10 & PCR & CSF \\
\hline Streptococcus pneumonieae & 10 & PCR & CSF \\
\hline Tick-borne encephalitis virus & 10,11 & $\lg$ & CSF, S \\
\hline Treponema pallidum & 2,10 & $\lg$ & S \\
\hline $\begin{array}{l}\text { Trypanosoma brucei gambiense/ } \\
\text { rhodesiense }\end{array}$ & 2 & $P C R, \lg$ & $S$ \\
\hline Trypanosoma cruzi & 2 & $\lg$ & $\mathrm{s}$ \\
\hline Varicella zoster virus & 10 & $P C R, \lg , \mathrm{Al}$ & CSF, S \\
\hline Variegated squirrel bornavirus-1 & 21 & PCR & CSF \\
\hline West Nile virus & 10,11 & $\lg$ & S \\
\hline Yellow fever virus & $2,9,11,17,21$ & $P C R, \lg$ & CSF, S, A \\
\hline Zika virus & 10 & $P C R, \lg$ & S \\
\hline
\end{tabular}

Evaluated pathogens with negative findings DOS Days after onset of symptoms, Ig Serology, Al pathogen specific CSF/serum antibody index, S Serum, Ag Antigen-Test, QFT Quantiferon test, $B$ Blood, RT Rapid test, $M$ Microscopy, $A$ autopsy tissue autoimmune-mediated encephalitis (21\%), while about $40 \%$ of the patients remain without a final diagnosis [2].

In our case, the clinical suspicion of encephalitis quickly emerged and was supported by results of lumbar puncture and EEG. In the initial phase of the disease, diagnostic imaging (CT and MRI) could not reveal a morphological correlate with these findings and the patient's symptoms. However, a vascular or malignant cause of the disease could be excluded in this way. HSV encephalitis is the most common sporadic form of encephalitis in Western Europe. There is an international consensus to carry out a rapid diagnosis using PCR from the CSF and to administer a empiric therapy with acyclovir. Such measures reduce the lethality of HSV encephalitis from about 70 to $30 \%$ [5].

Empiric antibiotic and antiviral treatment was immediately started upon admission to hospital according to the current guidelines of the German Society for Neurology $[6,7]$, so that there was no delay in therapy initiation. Although HSV-PCR from CSF in the early phase of HSV encephalitis does not reach a sensitivity of $100 \%$ [8], acyclovir therapy was terminated after 3 days. This discontinuation of the empirical acyclovir therapy was justified by the lack of strong clinical suspicion of a very rare 'PCR negative' HSV encephalitis: Repeated cranial imaging (CT and MRI) without abnormal findings and the first clinical improvement allowing an extubation after 6 days were the evidence for this therapeutic decision. After transfer to the university hospital, a second HSVPCR from CSF performed on day 10 - after an acyclovir break of several days - was also negative and underlined that HSV was extremely unlikely to be the causative pathogen of the patient's encephalopathy presented at this time. Moreover, a repeatedly normal serum CSF antibody specificity index for HSV throughout the disease duration (21 days) showed that HSV encephalitis diagnosed post mortem must indeed have developed towards the end of the clinical course (Table 3).

A travel-associated infectious disease was considered an important differential diagnosis from the very first moment due to the presented neurological symptoms associated with a journey abroad [9]. All relevant pathogens were examined after an evaluation of the potential exposure risk [10]. However, in this context, it must also be discussed, whether the very short duration of the stay abroad equals an appropriately long incubation period for an acute infection. Therefore, emerging viruses that may have been acquired before the journey, such as zoonotic Borna viruses (BoDV-1 and VSBV-1), were also taken into account.

In addition to the targeted search for pathogens, the 'extended' microbiological diagnosis in such a travelrelated case must include vaccines applied in a close temporal connection as well as medication already 

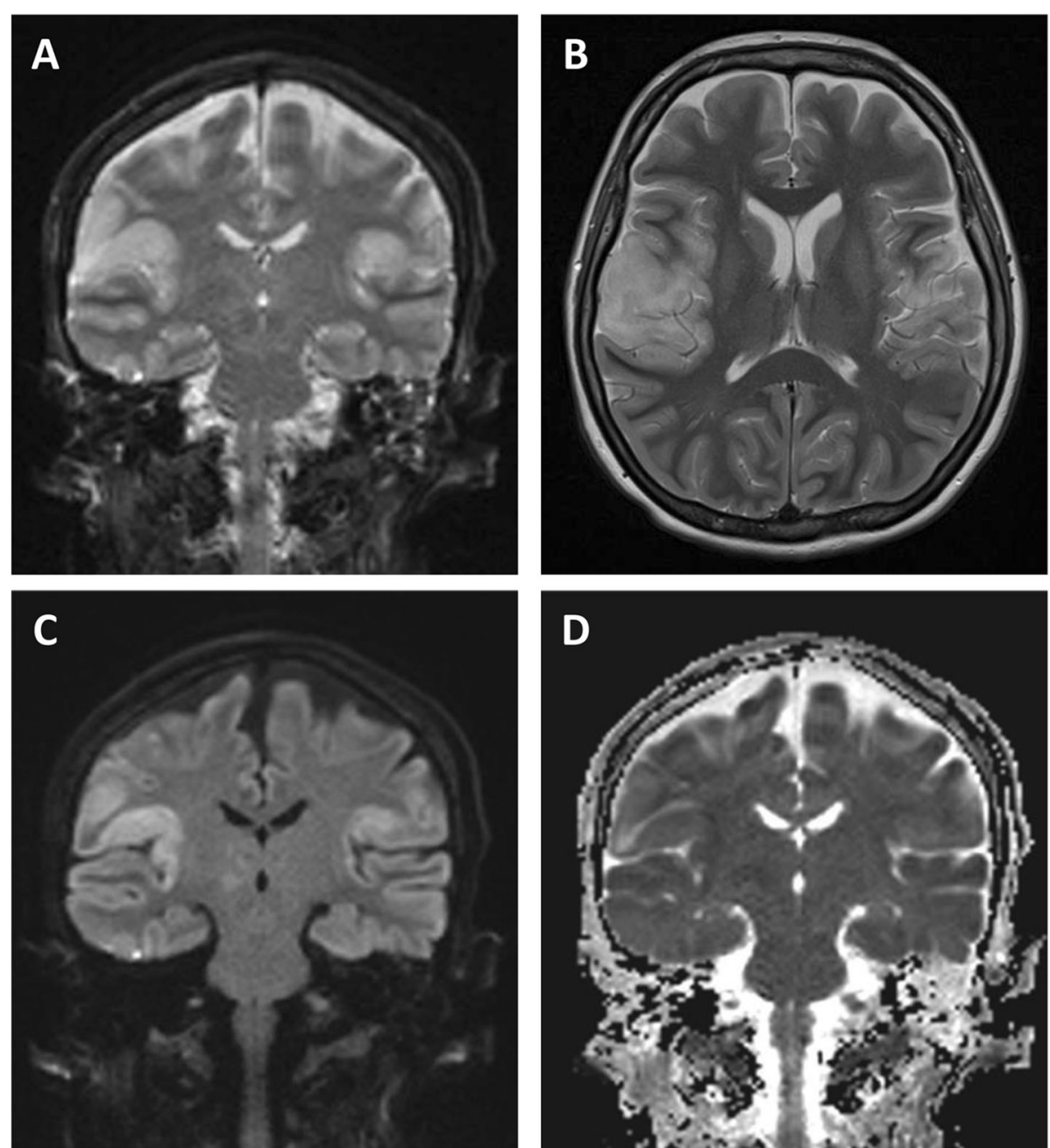

Fig. $3 \mathrm{CMRI}$ imaging. Cortical/subcortical oedema within insular and parietal lobe on coronal and axial T2w (a, b), coronal DWI with increased signal on B1000 image (c) and decreased ADC (apparent diffusion coefficient) (d) within the encephalitic lesion

administered on site. A first important aspect of the patient's travel-related vaccination record is the correctly administered yellow fever vaccination 2 weeks before departure. YEL-AND is a serious side effect after primary vaccination [11]. The frequency is given as approx. 0.8/ 100,000 doses. Typically, patients develop meningoencephalitis 14 (3-28) days after administration but recover without sequelae. This infection of the CNS by the vaccine virus itself can be detected by the detection of yellow fever vaccine RNA or yellow fever virusspecific antibodies in the cerebrospinal fluid [12]. Few data suggest that yellow fever vaccination may trigger an autoimmune response and cause symptoms such as Guillain-Barré syndrome, multiple sclerosis or acute demyelinating encephalomyelitis (ADEM) [13]. However, as described above, there was no evidence of YEL-AND in our case.
Another important point of the travel history is that haemorrhagic cystitis with proven Trichomonas infection was already treated with antibiotics during the stay in The Gambia. Even if the exact active substance was not traceable, a therapy with metronidazole seems to be very likely. Metronidazole-induced encephalopathies described in the literature differ in their typical clinical course from our case [14]. Nevertheless, we cannot exclude such a possible or other (unknown) drug side effect as the cause of the persistent impaired consciousness in the retrospective assessment of the case.

We had expected that the NGS analysis from the brain tissue samples would detect unanticipated or possibly even novel pathogens, which was, however, not the case. Nevertheless, reduced sensitivity remains a weakness of this method. In our case study, for example, an HSV load of $1000 \mathrm{Geq} / \mathrm{ml}$ detectable in serum by routine 


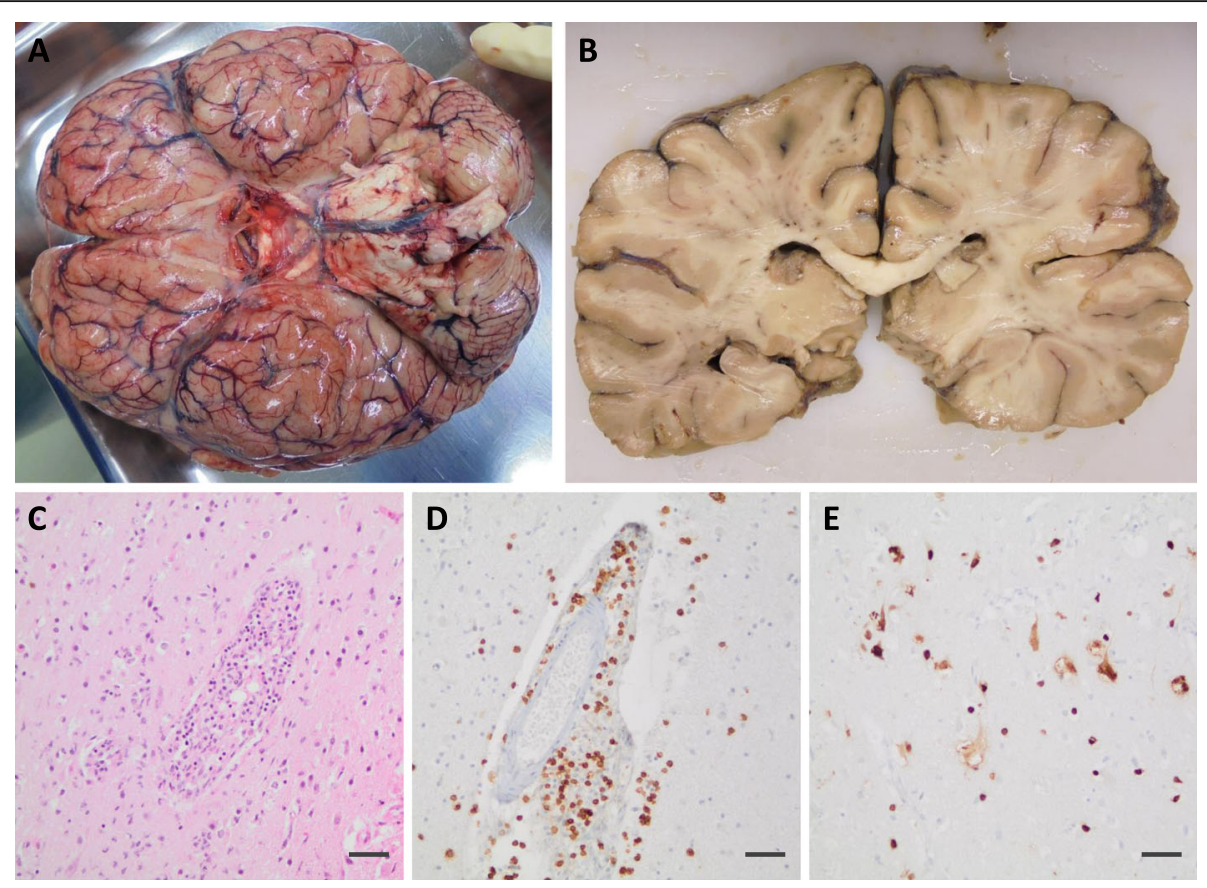

Fig. 4 Neuropathological autopsy findings. Oedematous swelling with sulcal effacement and signs of transtentorial and tonsillar herniation (a). Symmetrical, though remarkably compressed ventricular system reflecting the increased intracranial pressure (b). Histological examination showed lymphocytic meningoencephalitis with marked perivascular and intraparenchymal lymphocyte infiltration (c). The infiltrates are primarily composed of CD3-positive T-lymphocytes (d). Numerous infected neurons demonstrated by HSV-1 immunohistochemistry (e). Magnification (c)(e): 20x; Scale bar: $50 \mu \mathrm{m}$

PCR could not generate HSV reads in the NGS investigation of the serum at the same point in time (compare Tables 2 and 3). This may be relevant because it cannot be excluded that the initial phase of the disease was caused by an unknown pathogen other than HSV and not by autoimmune disease. The viral load in brain tissue may have fallen below the lower detection limit of the NGS analysis over the course of the disease. Nevertheless, in our case we estimate the probability of not being able to detect a previously unknown pathogen after 21 days of illness in a brain biopsy via NGS as low.

Even today, it is estimated that approximately half of all encephalitis cases remain without identification of a clear cause $[2,15]$. Despite advancing diagnostic options from multiplex PCR systems to NGS technology, this gap in clinical microbiology is not closed. Publications on NGS

Table 2 Results of NGS analysis

\begin{tabular}{lllll}
\hline Material & & RNA/DNA [ng/ $\mu$ l] & Reads total & Reads HSV-1 \\
\hline Frontal lobe & RNA & 0.47 & $4,252,804$ & $4188(0.10 \%)$ \\
Frontal lobe & DNA & 1.5 & $2,186,683$ & $490(0.02 \%)$ \\
Cerebellum & RNA & 0.39 & $4,983,018$ & 0 \\
Serum (DOS 21) & RNA & 0.42 & $2,523,808$ & 0 \\
\hline
\end{tabular}

metagenomic analyses in patients with encephalitis show that known and common encephalitis pathogens but also rare, unexpected, or even novel organisms can be detected in patient samples [16-18].

The HSV-reactivation presented as an atypical manifestation of HSV-1 encephalitis without the temporally and frontally accentuated haemorrhagic necroses which are typically observed on imaging and autopsy. Such atypical manifestations of HSV-1 encephalitis can be observed in immunosuppressed or critically ill patients [19-21] and impede making the correct diagnosis. Histological examination demonstrated pronounced lymphocytic meningoencephalitis with immunohistochemical detection of HSV-1 antigens. Due to the extensive destruction of the brain tissue, any signs, allowing conclusions towards the aetiology of the initial disease could not be assessed.

In animal models, the hypothesis that naturally occurring stressful situations in the host lead to reactivation of latent herpes viruses due to increased endogenous corticosteroid release was supported early on [22]. The effects of corticosteroids on the gene expression of the cell and latent virus, which occur a few hours after injection, can lead to an altered balance between herpes virus and neuron and can lead to the death of the neuron by 


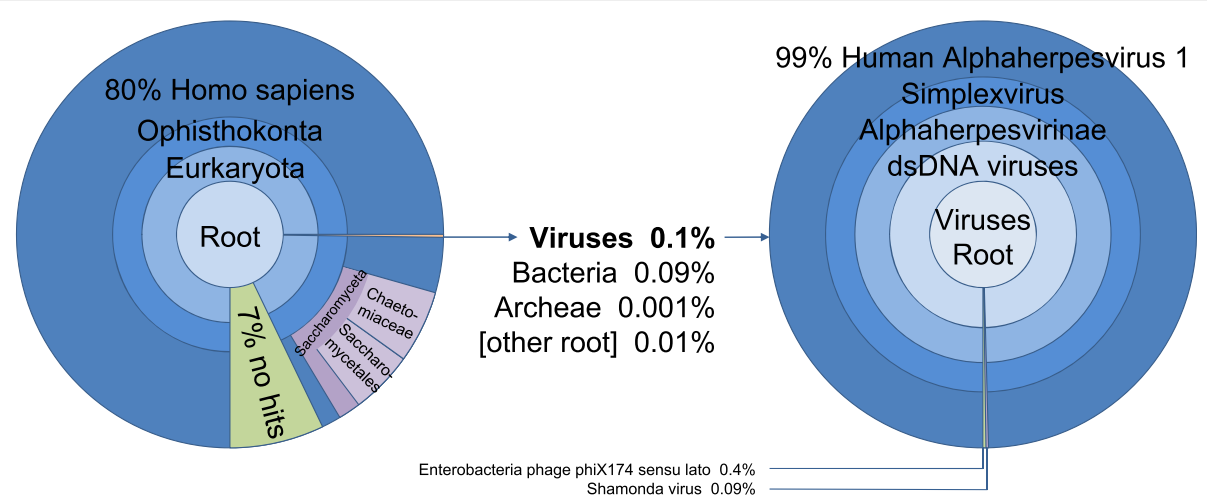

Fig. 5 NGS analysis. RNA was transcribed in CDNA and sequencing libraries were prepared using the NexteraXT DNA preparation kit following the manufacturer's instructions. Libraries were loaded and sequenced on an Illumina MiSeq sequencer using a V3 600 cycles kit. Taxonomic classifications of sequencing reads were performed with the Kraken software and visualized with the Krona tools. Left: Reads total, frontal lobe; Right: Reads, virus specific; frontal lobe

switching the virus into a lytic replication cycle, even with a single dose of dexamethasone.

Although it is well known that steroid therapy can cause HSV reactivation in neurons in animal models, only few cases have been reported in the literature in which HSV reactivation and encephalitis coincided with steroid therapy in humans [23]. Of note, most of the described treatment regimens consisted of a combination with other stress-inducing or immunosuppressive therapies such as irradiation or chemotherapy [24, 25]. Therefore, HSV reactivation and atypical herpesviral encephalitis should be considered as relevant differential diagnosis in iatrogenically immunosuppressed patients in general and especially after high-dose steroid therapy. Moreover, a recent study suggests that atypical presentations of HSV encephalitis might be more frequent than expected so far [26].

In summary, our case represents the reactivation of HSV-1 infection, likely triggered by steroid therapy in

Table 3 Results of testing for HSV

\begin{tabular}{llll}
\hline DOS & Specimen & HSV Analyte & Value \\
\hline 2 & CSF & DNA & negative \\
10 & CSF, serum & DNA & negative \\
10 & CSF, serum & $\mathrm{Al}$ & 1.4 \\
10 & serum & IgG & $32 \mathrm{AE} / \mathrm{ml}$ \\
21 & CSF & DNA & $1.4 \mathrm{Mio} \mathrm{Geq} / \mathrm{ml}$ \\
21 & serum & DNA & $1000 \mathrm{Geq} / \mathrm{ml}$ \\
21 & brain tissue & DNA & positive \\
21 & CSF, serum & $\mathrm{Al}$ & 0.5 \\
21 & serum & lgG & $27 \mathrm{AE} / \mathrm{ml}$ \\
\hline
\end{tabular}

Retrospective analysis of CSF and serum samples provided HSV DNA positive PCR results only for the shorty before death collected specimens (technical limit of detection (LOD) $=700 \mathrm{Geq} / \mathrm{ml}$, at $95 \%$ hit rate). Al = serum CSF antibody specificity index (normal range value $0.5-1.5$ ) the context of a pre-existing severe encephalitis of unknown cause. In order to not overlook newly occurred and potentially treatable entities, continuous re-evaluation of potential differential diagnoses, especially regarding opportunistic infections or reactivation of latent infections, is of utmost importance.

\section{Abbreviations}

ADC: Apparent diffusion coefficient; ADEM: Acute demyelinating encephalomyelitis; Al: Serum CSF antibody specificity index; CNS: Central nervous system; CSF: Cerebrospinal fluid; CT: Computed tomography; DNA: Desoxyribonucleic acid; DOS: Days after onset of symptoms;

EEG: Electroencephalography; HSV: Herpes simplex virus; i.v.: Intravenously; ICP: Intracranial pressure; LOD: Technical limit of detection; MRI: Magnetic resonance imaging; NGS: Next-generation sequencing; PCR: Polymerase chain reaction; RNA: Ribonucleic acid; Tid: Ter in die, which in Latin means three times a day; YEL-AND: Yellow fever vaccine-associated neurological disease

\section{Acknowledgements}

We would like to thank our colleagues at Munich Airportclinic and Klinikum Freising for their competent and caring care of the patient. We thank the family of the deceased for their consent to the publication of the case and regret their tragic loss.

\section{Authors' contributions}

$\mathrm{KD}$ and HWP treated the patient and collected clinical data; $\mathrm{AO}, \mathrm{SB}, \mathrm{CD}, \mathrm{AN}$, $\mathrm{SZ}$, and DT performed and interpreted classical, serological and molecular virological analyses; $\Pi$ performed and interpreted NGS analysis; VCR and AG performed the brain section and provided macro- and microscopic neuropathological diagnoses; $\mathrm{KS}$ and $\mathrm{HZ}$ analysed and interpreted $\mathrm{CT}$ and MRI scans; PE performed and interpreted routine laboratory testing including autoimmune-antibody testing; $\mathrm{AO}$ obtained ethical approval; $\mathrm{AO}$ and VCR wrote the manuscript. All authors critically read, edited and approved the manuscript.

\section{Funding}

None.

\section{Availability of data and materials}

Data is available upon request. The corresponding author Andreas Osterman should be contacted.

\section{Ethics approval and consent to participate}

The need for approval was waived by the Ethics Committee (Chairman Prof. Dr. W. Eisenmenger), Faculty of Medicine of the Ludwig-MaximilianUniversity Munich (project reference number 18-663 UE). 


\section{Consent for publication}

Written informed consent for the publication of this case report and any accompanying images was obtained from the patient's family.

\section{Competing interests}

The authors declare that they have no competing interests.

\section{Author details}

'Max von Pettenkofer Institute, Virology, Faculty of Medicine, LMU Munich, Pettenkoferstraße 9a, D-80336 Munich, Germany. ${ }^{2}$ German Center for Infection Research (DZIF), partner site Munich, Pettenkoferstraße 9a, D-80336 Munich, Germany. ${ }^{3}$ Center for Neuropathology and Prion Research, Faculty of Medicine, LMU Munich, Feodor-Lynen-Straße 23, D-81377 Munich, Germany. ${ }^{4}$ Robert Koch Institute, Center for Biological Threats and Special Pathogens, Highly Pathogenic Viruses ZBS-1, Seestraße 10, D-13353 Berlin, Germany. ${ }^{5}$ Institute of Laboratory Medicine, University Hospital Campus Großhadern, LMU Munich, Marchioninistraße 15, D-81377 Munich, Germany. ${ }^{6}$ Department of Neuroradiology, University Hospital Campus Großhadern, LMU Munich, Marchioninistraße 15, D-81377, Munich, Germany. ${ }^{7}$ Bundeswehr Institute of Microbiology, Munich, Neuherbergstraße 11, D-80937 Munich, Germany. ${ }^{8}$ Department of Neurology, University Hospital Campus Großhadern, LMU Munich, Marchioninistraße 15, D-81377 Munich, Germany. ${ }^{9}$ Bernhard Nocht Institute for Tropical Medicine, Hamburg, Bernhard-Nocht-Straße 74, D-20359 Hamburg, Germany.

Received: 13 December 2019 Accepted: 6 February 2020

Published online: 18 February 2020

\section{References}

1. Steiner I, Budka H, Chaudhuri A, Koskiniemi M, Sainio K, Salonen O, et al. Viral meningoencephalitis: a review of diagnostic methods and guidelines for management. Eur J Neurol. 2010;17(8):999-e57.

2. Granerod J, Ambrose HE, Davies NW, Clewley JP, Walsh AL, Morgan D, et al. Causes of encephalitis and differences in their clinical presentations in England: a multicentre, population-based prospective study. Lancet Infect Dis. 2010;10(12):835-44.

3. Graus F, Titulaer MJ, Balu R, Benseler S, Bien CG, Cellucci T, et al. A clinical approach to diagnosis of autoimmune encephalitis. Lancet Neurol. 2016; 15(4):391-404

4. Venkatesan A, Michael BD, Probasco JC, Geocadin RG, Solomon T. Acute encephalitis in immunocompetent adults. Lancet (London, England). 2019; 393(10172):702-16.

5. Whitley RJ. Herpes simplex encephalitis: adolescents and adults. Antivir Res. 2006;71(2-3):141-8.

6. Meyding-Lamadé U, et al. Virale Meningoenzephalitis, S1-Leitlinie, 2018, in: Deutsche Gesellschaft für Neurologie (Hrsg.), Leitlinien für Diagnostik und Therapie in der Neurologie. Online: www.dgn.org/leitlinien (Abgerufen am 30 Sept 2019).

7. Pfister H-W, et al. S2k-Leitlinie Ambulant erworbene bakterielle (eitrige) Meningoenzephalitis im Erwachsenenalter. 2015. In: Deutsche Gesellschaft für Neurologie, Hrsg. Leitlinien für Diagnostik und Therapie in der Neurologie. Online: www.dgn.org/leitlinien (Abgerufen am 11 Oct 2019).

8. Rice CM, Yadav S, Boyanton B, Subedi P, Band J. Clinical problem-solving. A creeping suspicion. N Engl J Med. 2014;371(1):68-73.

9. Thompson H, Thakur K. Infections of the central nervous system in returning travelers and immigrants. Curr Infect Dis Rep. 2017;19(11):45.

10. Bharucha T, Manji H. Montezuma's revenge': neurological disorders in the returning traveller. Pract Neurol. 2018;18(5):359-68.

11. Oliveira AC, Maria Henrique da Mota L, Dos Santos-Neto LL, De Carvalho JF, Caldas IR, Martins Filho OA, et al. Occurrence of Autoimmune Diseases Related to the Vaccine against Yellow Fever. Autoimmune Dis. 2014:2014:473170

12. Staples JE, Gershman M, Fischer M. Yellow fever vaccine: recommendations of the Advisory Committee on Immunization Practices (ACIP). MMWR Recom Rep. 2010;59(Rr-7):1-27.

13. McMahon AW, Eidex RB, Marfin AA, Russell M, Sejvar JJ, Markoff L, et al. Neurologic disease associated with 17D-204 yellow fever vaccination: a report of 15 cases. Vaccine. 2007;25(10):1727-34.

14. Sorensen CG, Karlsson WK, Amin FM, Lindelof M. Metronidazole-induced encephalopathy: a systematic review. J Neurol. 2020;267(1):1-13.
15. Brown JR, Bharucha T, Breuer J. Encephalitis diagnosis using metagenomics: application of next generation sequencing for undiagnosed cases. J Infect. 2018;76(3):225-40

16. Chan BK, Wilson T, Fischer KF, Kriesel JD. Deep sequencing to identify the causes of viral encephalitis. PLoS One. 2014;9(4):e93993.

17. Guan H, Shen A, Lv X, Yang X, Ren H, Zhao Y, et al. Detection of virus in CSF from the cases with meningoencephalitis by next-generation sequencing. J Neurovirol. 2016;22(2):240-5.

18. Perlejewski K, Popiel M, Laskus T, Nakamura S, Motooka D, Stokowy T, et al. Next-generation sequencing (NGS) in the identification of encephalitiscausing viruses: unexpected detection of human herpesvirus 1 while searching for RNA pathogens. J Virol Methods. 2015;226:1-6.

19. Tan IL, McArthur JC, Venkatesan A, Nath A. Atypical manifestations and poor outcome of herpes simplex encephalitis in the immunocompromised. Neurology. 2012;79(21):2125-32.

20. Sermer DJ, Woodley JL, Thomas CA, Hedlund JA. Herpes simplex encephalitis as a complication of whole-brain radiotherapy: a case report and review of the literature. Case Rep Oncol. 2014;7(3):774-9.

21. Silvano G, Lazzari G, Resta F, Buccoliero G, Pezzella G, Pisconti S. A Herpes simplex virus-1 fatal encephalitis following chemo-radiotherapy, steroids and prophylactic cranial irradiation in a small cell lung cancer patient. Lung cancer (Amsterdam, Netherlands). 2007;57(2):243-6.

22. Rock D, Lokensgard J, Lewis T, Kutish G. Characterization of dexamethasone-induced reactivation of latent bovine herpesvirus 1. J Virol. 1992;66(4):2484-90.

23. Doherty MJ, Baxter AB, Longstreth WT Jr. Herpes simplex virus encephalitis complicating myxedema coma treated with corticosteroids. Neurology. 2001;56(8):1114-5

24. Graber JJ, Rosenblum MK, DeAngelis LM. Herpes simplex encephalitis in patients with cancer. J Neuro-Oncol. 2011;105(2):415-21.

25. Saito M, Kiyozaki H, Obitsu T, Imoto H, Taniyama Y, Takata O, et al. Herpes simplex virus-1 encephalitis induced by chemoradiotherapy and steroids in an esophageal cancer patient: a case report. BMC Cancer. 2016;16:233.

26. Bewersdorf JP, Koedel U, Patzig M, Dimitriadis K, Paerschke G, Pfister HW, et al. Challenges in HSV encephalitis: normocellular CSF, unremarkable CCT, and atypical MRI findings. Infection. 2019;47(2):267-73.

\section{Publisher's Note}

Springer Nature remains neutral with regard to jurisdictional claims in published maps and institutional affiliations.

Ready to submit your research? Choose BMC and benefit from:

- fast, convenient online submission

- thorough peer review by experienced researchers in your field

- rapid publication on acceptance

- support for research data, including large and complex data types

- gold Open Access which fosters wider collaboration and increased citations

- maximum visibility for your research: over $100 \mathrm{M}$ website views per year

At $\mathrm{BMC}$, research is always in progress.

Learn more biomedcentral.com/submissions 